\title{
Using Image Analysis Software to Create a Physical Skull Model for the Facial Reconstruction of a Wrapped Akhmimic Mummy
}

\author{
Heather Gill-Robinson ${ }^{1}$, Jonathan Elias ${ }^{2}$, Frank Bender ${ }^{3}$, Travis T. Allard ${ }^{4}$ \\ and Robert D. Hoppa ${ }^{4}$ \\ ${ }^{1}$ Department of Sociology-Anthropology, North Dakota State University, Fargo, USA \\ ${ }^{2}$ Director, Akhmim Mummy Studies Consortium, Harrisburg, USA \\ ${ }^{3}$ Forensic Sculptor, Akhmim Mummy Studies Consortium \\ ${ }^{4}$ Department of Anthropology, University of Manitoba, Winnipeg, Canada
}

As part of a larger program of research, several mummies from the city of Akhmim have undergone Computed Tomography (CT) scanning. Analysis of the images of these mummies is providing insight into the age, sex and health of these individuals. In an effort to gain an understanding of how specific people from the city of Akhmim may have looked in life, forensic facial reconstruction was undertaken. This paper is a discussion of the review, analysis and interpretation of the two-dimensional CT images of an Akhmimic mummy through the preparation of virtual on-screen and physical three-dimensional models, including a printed skull.

Keywords: mummies, Egypt, CT imaging, 3D printing, forensic facial reconstruction.

\section{Introduction}

\subsection{Site of Akhmim}

Located at a strategic bend in the River Nile (470 km south of Cairo), the site of Akhmim was one of ancient Egypt's greatest cities. Its importance as a religious center was matched by its significance in regional administration, textile manufacture and trade. There is evidence of continuous habitation at the site extending back over 5000 years.

Consequently, the cemetery district at Akhmim is enormous, consisting of three major necropolis areas: al-Salumuni in the north; the alHawawish cliff site (or al-Medinah) in the southeast, and the al-Hawawish Ridge Cemetery in between. Kuhlmann's 1983 overview of Akhmim's cemeteries [1] covered each of these areas and provided basic descriptions of visible tomb cuttings. Scholarly interest has focused on the inscribed and decorated tombs of the al-Medinah necropolis area. Nevertheless, the largely undecorated chambers found in the al-Hawawish Ridge Cemetery (Kuhlmann's "Friedhof A") hold greater promise for epidemiological studies of the ancient population of Akhmim. Abundant skeletal material lies on the cemetery's surface and extends for a considerable distance. It attests the activity of late $19^{\text {th }}$ century excavators, who reported [2] the discovery of thousands of mummies in this area, recovered from single and multi-chambered tombs cut into a series of silt and gravel covered limestone bluffs, directly east of the modern cultivation.

There are strong indications that the al -Hawawish Ridge Cemetery was intensively used during the Third Intermediate Period (1069 - $664 \mathrm{BC}$ ) and subsequent eras. A very large component of the cemetery population seems to date to the period after $664 \mathrm{BC}$, and relate specifically to the still poorly understood phases of Persian domination (525-404 BC), resurgent native dynasties (404-343 $\mathrm{BC}), 2^{\text {nd }}$ Persian interlude (343-332 BC), and the AlexandrinePtolemaic period (332-30 BC). The high status 
burials found in the al-Hawawish Ridge Cemetery belong to members of priestly families who served the important god Min during a time when Akhmim had become a focal point of native resistance to the Ptolemaic regime. We suspect that the ethnic configuration of Akhmim's population became increasingly diverse around that time, as groups that were displaced due to unrest in other provinces in Southern Egypt moved into the Akhmim region.

Facial reconstruction of mummies from the alHawawish Ridge Cemetery therefore presents an opportunity to better understand the configuration of the Akhmimic population during a critical period of Egyptian history. These times witnessed momentous changes in Egyptian culture, as native communities struggled to maintain their autonomy under changing masters. The apparatus of the Persian and Ptolemaic administrations brought on widespread social and economic changes which can be expected to have left evidentiary traces on the population itself.

\subsection{History of the Mummy}

The subject of this study in facial reconstruction was named either Ta-irty or Ta-irty-bai. She was a woman who is estimated to have reached the age of 35 to 45 , before dying of unknown causes in the mid- to late $3^{\text {rd }}$ century BC (C14 $2230+/-$ yrs BP).[3] She was afflicted in life by moderate spinal scoliosis which may have resulted over time as a complication of a leg reduced in length due to improper setting of an oblique fracture of the right femur.

Ta-irty's mummy came to the College of Wooster, Ohio, USA in 1885, still lying in its original coffin (Figure 1). Hers was one of four mummies legally purchased by missionaries Rev. John Giffen and Rev. John R. Alexander, then in Egypt distributing Bibles on behalf of the American Reformed church. Following the discovery of hundreds of mummies at the site of Akhmim (April 1884), a group of twelve were obtained by dealers and brought northward to Asyut, where the missionaries happened to be based. Giffen and Alexander secured a part of this group for their respective institutions. Each mummy then cost $\$ 8.00$ US. Rev. Alexander's alma mater, the College of

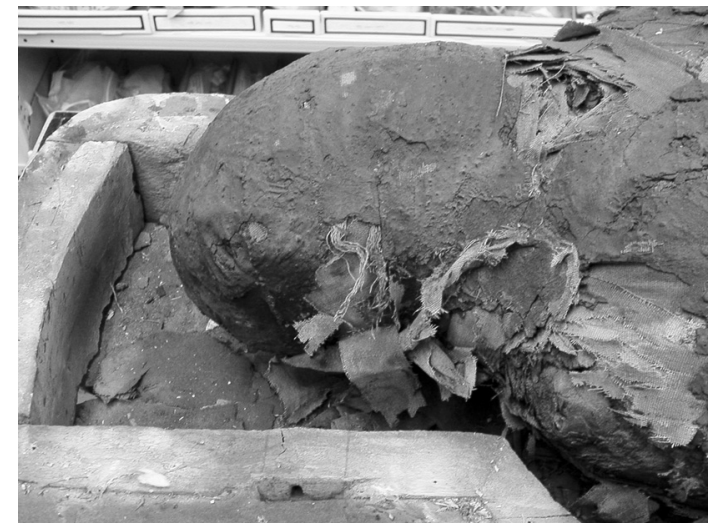

Fig. 1.Ta-irty in her original coffin (AMSC).

Wooster, houses Ta-irty's mummy in its Art Museum (Inv. No. 01.1a-c); a second female mummy, named Pesed, is owned by Giffen's alma mater, Westminster College, New Wilmington, Pennsylvania (WC Inv. No. 48). A third mummy, named Muthotep remains in a small collection in Asyut to this day, and a fourth was unfortunately reported to have been lost in a fire on the campus of Eskine College in Due West, South Carolina. Ta-irty's mummy was nearly destroyed by fire in 1901, but survived, and became available for later examination. [5]

\section{Methods}

\subsection{Radiology}

Radiological examination of Ta-irty was first undertaken in 1964. Dr. Dixon of the Wooster Clinic presided. The Akhmim Mummy Studies Consortium collaborated with the College of Wooster Art Museum to undertake the first CT scan of Ta-irty as part of an exhibition being planned for the museum's galleries.

For the current project, a CT scan was performed at the Healthpoint imaging facility of Wooster Community Hospital on October 27, 2004. The body was scanned using a GE Medical Lightspeed Ultra. The body was scanned at $120 \mathrm{kV}$ with a dose of $163.9900 \mathrm{mAs}$. The protocol followed produced a slice thickness of $1.25 \mathrm{~mm}$ at $1.25 \mathrm{~mm}$ intervals. This resulted in a full body scan of 1199 slices. The raw CT scan images, which had a pixel size of $0.781 \mathrm{~mm}$, were stored on MOD and loaded onto the facility's PAX system. Subsequently, the images 
were fed into a Terarecon $\AA$ 3D reconstructive program for initial analysis. Additional 3D digital imaging was performed by staff of Pinnacle Health System in Harrisburg, PA, using a Vitrea $2 ®$ work station (Figure 2 ).

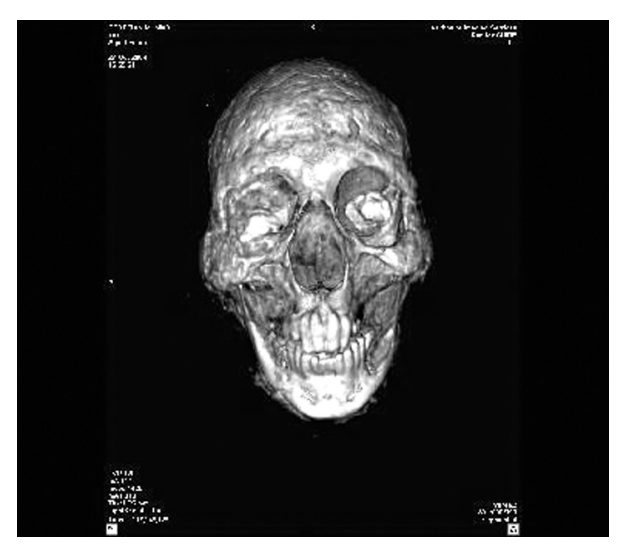

Fig. 2. 3D rendering of Ta-irty (Vitrea $2 \AA)$.

\subsection{Image Editing}

When project staff decided to produce a full facial reconstruction of Ta-irty as part of its overall research program, a collaboration was established with the University of Manitoba's Bioanthropology Digital Image Analysis Laboratory (BDIAL). DICOM files were forwarded to the BDIAL and editing of these images was undertaken to produce an accurate $3 \mathrm{D}$ rendering of Ta-irty's skull.

Image editing of the DICOM files was undertaken in Mimics 9.0 medical imaging software by Materialise. DICOM images are automatically converted to proprietary Mimics project files in the software and all editing takes place within the project files; DICOM images remain intact. Mimics allows visualization of the CT data in axial, sagittal and coronal views, as well as the generation of virtual three-dimensional models. These 3D models can then be exported as polygon meshes, using the stereolithography (STL) file format for interfacing with rapid prototyping applications.

Since the primary purpose of this stage of image analysis for Ta-irty was to produce a physical model to serve as a base for facial reconstruction, editing focused on the skull region. Ta-irty is a wrapped mummy; an estimated eight to ten layers of resin-coated linen bandages overlay the face and head. Part of the challenge of facial reconstruction of a wrapped Egyptian mummy is the delicate task of removing bandages and skin (Figure 3) to access the underlying facial skeletal structure.

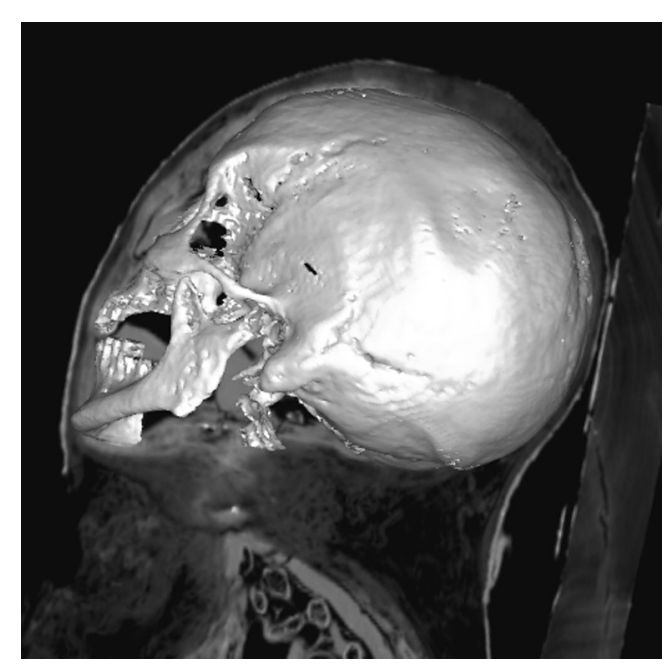

Fig. 3. Sagittal view of Ta-irty showing partial 3D skull model, with layers of skin and bandage over face visible.

The first stage in editing was to crop out the skull region and separate it from the rest of the body. This considerably reduced the file size, making the editing process more manageable. The data was then resliced at $0.5 \mathrm{~mm}$ intervals perpendicular to the sagittal plane, to compensate for the slightly oblique angle at which Ta-irty's head rested. Next, extraneous material, such as evidence of the coffin and the outermost layers of bandages, were removed virtually, using a drawing tablet and the Mimics editing functions. Mimics allows different colored masks to be created, representing different stages in the editing process or regions of interest. Several masks were created during this early phase of editing.

Thresholding, based on grayscale values reflecting different levels of radiopacity, is used to distinguish one material from another; it is usually possible, for example, to differentiate between cloth, skin, bone and soft tissue. Initial attempts to edit out the bandage layers using thresholding resulted in the loss of most small, fragile facial bones, which have similar threshold values to the bandages in the images due to 
their thin and delicate nature. Specifically, sections of the palate, ethmoid, sphenoid and the nasal spine essentially disappeared. The use of thresholding was further complicated by the presence of large amounts of resin, an artifact of the mummification process, in both the posterior portion of the cranial cavity and throughout the nasal cavities. The radiopacity of various structures may appear similar in standard views of the CT scans, so identifying and separating distinct structures, particularly in ancient mummified material, is difficult. Mimics offers a pseudocolors feature, which enables the user to view areas with artificial colors. This feature proved particularly useful for distinguishing between resin and bone in the nasal region, or distinguishing between desiccated skin layers and bone in the area of the face, although it was still not possible to use only thresholding to remove the bandage layers close to the face.

Manual editing of each individual slice was necessary, in order to ensure that all layers of bandage and skin were removed, but that the bony structures remained intact. This timeconsuming, but necessary, step ensured that the final virtual and physical models created from the CT scans were completely accurate. Editing was undertaken on the axial, coronal or sagittal view, depending on which offered the best view of the structure, although the original scan view (in this case coronal) provided the best result.

\subsection{Model Preparation}

Virtual 3D models were rendered periodically during the thresholding and manual editing processes in order to view the completeness and accuracy of the editing. These models could be rotated or viewed in cross-section to check the internal and external structures of the skull from all angles.

When all editing was completed, a stereolithography (STL) file of the virtual model was created and exported for printing the physical model. The STL file was then printed using a Z-Corporation Z406 3D printer. The Z406 printer creates the 3D model using a plaster-based powder and binder solution, putting down a layer of plaster $0.1 \mathrm{~mm}$ thick, followed by a layer of binder. This process was repeated until a complete three-dimensional model was created. The model was then removed from the printer, cleaned and infiltrated with cyanoacrylate for additional strength for the facial reconstruction process (Figures 4 and 5).

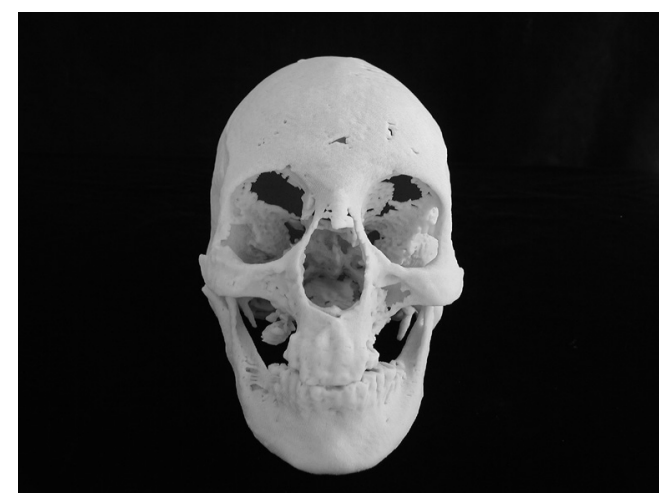

Fig. 4. Frontal view of the 3D-printed skull model.

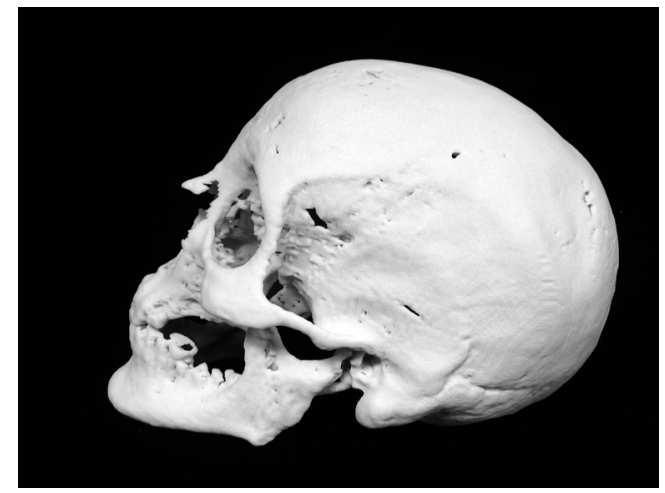

Fig. 5. Side view of the 3D-printed skull model.

\subsection{Facial Reconstruction}

The plaster model of the skull was then utilized by one of us (FB) as the core element of a full sculptural reconstruction according to accepted anthropological tables for soft tissue calculation. $[6,7]$ The reconstruction was created using the Gerasimov method, using the plaster skull model as a base. Markers were applied to the model to indicate population-appropriate soft tissue depths. Modeling clay was used to reproduce the facial muscles, which were then positioned on the basis of anatomical location and the tissue depth markers. A second layer of clay, representing the skin, was placed over the muscle structure to finish the appearance of 
the face and head. The final reconstruction is presented in Figure 6.

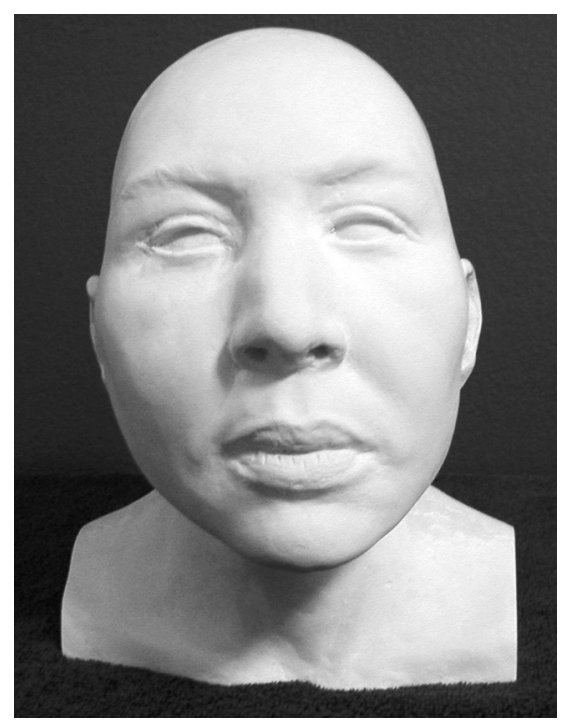

Fig. 6. Facial reconstruction of Ta-irty (F. Bender).

\section{Results}

Although there is substantial work to be done to fully analyze the images of Ta-irty, the preparation of the facial reconstruction is an important contribution to the interpretation of this individual. This is a crucial first step in a long term analysis of the ethnic diversity of the ancient Akhmimic population. Through the process of image editing, model preparation and creation of the facial reconstruction, several aspects of the mummification method were also identified.

Through visualization of CT images, it was obvious that no brain material remained in the skull. By closely examining the condition of the nasal region, it was possible to identify that Ta-irty had undergone excerebration through the right nasal cavity, which was a prevalent practice in Ptolemaic Akhmim. Furthermore, although the presence of resin in the cranium is normal in Akhmimic mummies, the large amount of resin in the posterior portion of Tairty's cranium is unusual. There is stratification of the resin visible on the images; it is possible that the material was introduced in two or more stages during mummification.

Ta-irty also has ante-mortem tooth loss to her maxillary dentition. Although the mandibular dentition appears to be complete with signs of wear, there are several teeth missing in the maxilla. Five anterior teeth are present, along with the third molars on both sides. First and second molars on both sides were lost ante-mortem, as were both premolars on both sides and one of the canine teeth. The alveolar bone has completely resorbed in these areas. Analysis of the dental loss and changes to the maxillary regions are ongoing.

\section{Discussion}

The importance of radiology to the study of ancient human remains is undisputed. Nearly a decade ago at the $2^{\text {nd }}$ World Congress on Mummy Studies a single paper discussed the "experimental" use of CT-scanning in an attempt to diagnose pathology on a South American mummy [8]. At the recent $5^{\text {th }}$ World Congress on Mummy Studies hosted by Italy in September 2004, more than 20 papers and posters were based on the use of CT scanning and $3 \mathrm{D}$ virtual reconstruction, mainly for visualization and animation. CT scanning and 3D virtual reconstruction have become routine for visualization, but it appears that many projects are not extending the use of virtual technology to the diagnosis and interpretation of trauma.

CT scans are the most beneficial method of imaging all types of mummies. The collection of three-dimensional data that can be used for archival purposes, or for virtual or physical modeling, is non-invasive, relatively inexpensive and readily available. Two decades ago, facial reconstructions from CT scans of Egyptian mummies were created using fibreboard templates traced from the skull outlines. Key reconstruction points such as the external auditory meatus and inferior orbital margins were identified on the fibreboard for guidance. Once the fibreboard structure was securely constructed, the three-dimensional surface structure was made from wax or modeling clay [9].

More recently, rapid prototyping technologies such as stereolithography, which allow for the creation of a physical model of an object, have been occasionally undertaken in the study of Egyptian mummies [eg. 10, 11, 12, 13, 14, 15]. Although the use of radiography and CT scanning for the diagnostic evaluation of skeletons and mummies is not unusual, stereolithography 
has been limited and is most often used for the creation of models of the skull to facilitate facial reconstruction. In one early project, stereolithography was used to reproduce the skull of the 5,300-year-old Tyrolean Ice Man [16]. This model was created to permit multiple analyses and enhanced interpretation of the mummy, rather than for facial reconstruction. Recently, Cesarani et al. [17] used a laser sintering system to produce a resin skull model. Physical facial reconstruction based on the resin model was then undertaken with good results. The three-dimensional printing method used in this project has not been widely applied in mummy studies, although recent work with peat bog mummies from northern Germany has clearly demonstrated its potential for the anthropological analysis of ancient human remains [18].

One of the key strategies of relaying the past is reconstruction of the persons whose lives are being investigated. It is important to be able to demonstrate aspects of the lifestyle and appearance of the individual or population. The preparation of the facial reconstruction, which will be incorporated into a museum exhibition, is an important aspect of disseminating research on Akhmim mummies to the public - in this case, through a reconstruction of Ta-irty, as she may have looked in life.

Ancient communities can be better understood by reconstructing the appearance of persons belonging to them. The reconstruction of facial characteristics is an important analytical tool that contributes greatly to the study of a community's epidemiology, ethnic diversity, and lifestyle. The preparation of Ta-irty's forensic facial reconstruction, which will be incorporated into a museum exhibition about the larger community of ancient Akhmim, is the initial phase of disseminating important epidemiological and anthropological research to the public.

\section{Conclusion}

Non-invasive technology, such as CT scanning, is essential to the study and interpretation of all types of human mummies. In the case of Egyptian mummies, such as Ta-irty, the bodies may be encased in layers of wrappings and enclosed in one or more coffins. To preserve these important resources and protect the human remains, imaging and three-dimensional reconstruction provide the opportunity to examine and analyze the mummy without unwrapping. Forensic facial reconstruction, as part of a larger program of imaging and analysis, enables researchers and members of the public to visualize people from the past.

\section{Acknowledgments}

The authors would like to thank the radiological staffs of Healthpoint Clinic, Wooster Ohio (particularly Dr. Pamela Maguire, Kim Napier, Dan Grabowski, and Mr. Bill Sheron), and Pinnacle Health System, Harrisburg, PA (particularly, Dr. Paul Potok and Mr. Randy Lykins). Special thanks to Kitty McManus Zurko, and Dr. Stephen Lucey of the College of Wooster Art Museum, who permitted AMSC the opportunity to research Ta-irty's mummy. Archival documentation relating to the mummy's arrival in the US was provided to the authors by Dr. Samuel Farmerie of Westminster College, New Wilmington, PA. This research was supported in part by the Canada Research Chairs program.

\section{References}

[1] K.P. KuHLManN, Materialien zur Archaologie und Geschichte des Raumes von Achmim, Sonderschrift Deutsches Archaologisches Institute Abteilung Kairo 11, P. von Zabern, Mainz Am Rhein (1983)

[2] G. MASPERO, Notes. Nature, 29 (1884), pp. 603

[3] J.P. ELIAS, CT Scan Reconnaissance of Mummy AMSC 3 (College of Wooster Art Museum no. 01.1a) AMSC Research Report (2005), pp. 10

[4] J.W. Hole, Jr. Human Anatomy and Physiology, $5^{\text {th }}$ Edition, (1990), pp. 330. Wm. C. Brown Publishers, Dubuque, IA

[5] D. McKeE, An Eventful Passage for the Lady Pest Ma Rheres, Westminster Magazine Fall (1994), pp. $14 \& 76$

[6] J.S. RHINE AND H.R. CAMPBELL, Thickness of facial tissues in the American Blacks, Journal of Forensic Sciences (1980) 25, pp. 847-858.

[7] J.S. Rhine, C.E. Moore AND J.T. Weston, (eds.). Facial Reproduction: Tables of Facial Tissue Thickness of American Caucasoids in Forensic Anthropology. (1982) Maxwell Museum Technical Series No.1, University of New Mexico, Albuquerque. 
[8] K. Reinhard, S. Guillén, J. Stavas And D.K. MeIER, Non-destructive analysis of Mitas Chiribaya mummy from Arica, Chile. In Studies on Ancient Mummies and Burial Archaeology: Proceedings of the II World Congress on Mummy Studies held at the city of Cartagena, Columbia, February of 1995. (F. Cárdenas-Arroyo and C. Rodríguez-Martín, Eds.). (2001), pp. 227-235. Instituto Canario de Bioantropologiá and Departamento de Antropologiá, Universidad de Los Andes, Bogotá

[9] R.A.H. NEAVE, The reconstruction of skulls for facial reconstruction using radiographic techniques, In Science and Egyptology (R.A. David, Ed.). (1986), pp. 329-333. Manchester University Press, Manchester.

[10] H. HJALGRIM, N. LYNNERUP, M. LIVERSAGE AND A. ROSENKLINT, Stereolithography: potential applications in anthropological studies, American Journal of Physical Anthropology, 97 (1995), pp. 329-333.

[11] S. Hughes, R. WRIGHT AND M. BARRY, Virtual reconstruction and morphological analysis of an ancient Egyptian mummy, Australasian Physical and Engineering Sciences in Medicine, 28 (2005), pp. 122-127

[12] F. Cesarani, M.C. Martina, A. Ferraris, R. GRILlETtO, R. BOANO, E.F. MAROCHETTI, A.M. DONALDONI AND G. GANDINI, Whole-body threedimensional multidetector CT of 13 Egyptian human mummies, American Journal of Roentgenology, 180 (2003), pp. 597-606.

[13] R.J. JANSEN, M. Poulous, W. TACONIS AND J. STOKER, High-resolution spiral computed tomography with multiplanar reformatting, 3D surface- and volume rendering: a non-destructive method to visualize ancient Egyptian mummification techniques, Computerized Medical Imaging and Graphics 26 (2002), pp. 211-216.

[14] H. HofFMAn, W.E. TORRES AND R.D. ERnST, Paleoradiology: advanced CT in the evaluation of nine Egyptian mummies, Radiographics, 22 (2002), pp. 377-385.

[15] C. Wilkinson, B. BRIER, R. NEAVE AND D. SMith, The facial reconstruction of Egyptian mummies and comparison with the Fayum portraits, In Mummies in a New Millennium: Proceedings of the $4^{\text {th }}$ World Congress on Mummy Studies, Nuuk, Greenland, September $4^{\text {th }}$ to $10^{\text {th }}$, 2001. (N. Lynnerup, C. Andreasen and J. Berglund, Eds.) . (2003), pp. 141146. Greenland National Museum and Archives and Danish Polar Center, Copenhagen.

[16] D. ZUR NEDDEN, R. KNAPP, K. WICKE, W. JUDMAIER, W.A. MURPHY, H. SEIDLER AND W. PLATZER, Skull of a 5,300-year-old-mummy: reproduction and investigation with CT-guided stereolithography, Radiology, 193 (1994), pp. 269-272.

[17] F. Cesarani, M.C. Martina, R. Grilletto, R. BOANO, A.M. DONADONI ROVERI, V. CAPUSSOTTO, A. GiUliano, M. CELIA AND G. GANDINI, Facial reconstruction of a wrapped Egyptian mummy using MDCT, American Journal of Roentgenology, 183 (2004), pp. 755-758.
[18] H. GILL-Robinson, The Bog Bodies of the Archaeologisches Landesmuseum, Schloss Gottorf, Schleswig, northern Germany. Unpublished PhD Thesis, Department of Anthropology, University of Manitoba, Winnipeg, Canada, (2005).

$$
\begin{array}{r}
\text { Received: December, } 2005 \\
\text { Accepted: February, } 2006 \\
\text { Contact addresses: } \\
\text { Heather Gill-Robinson } \\
\text { Fargo, North Dakota } \\
\text { USA } \\
\text { Minard Hall } \\
\text { North Dakota State University } \\
\text { Fartment } \\
\text { e-mail: Heather.Gill-Robins on@ndsu. edu } \\
\text { Jonathan Elias } \\
\text { P.O. Box 84 } \\
\text { USA } \\
\text { Akhmim Mummy Studies Consortium } \\
\text { Harrisburg, PA 17108-0084 } \\
\text { USA } \\
\text { e-mail: director@ams cres earch. com }
\end{array}
$$

HeAther GiLl-Robinson is Assistant Professor of Anthropology at North Dakota State University. Her research has included the analysis of Iron Age peat bog mummies from northern Germany and the recent work with the mummies from Akhmim.

JONATHAN Elias is Director of the Akhmim Mummy Studies Consortium, and Managing Curator of Ptolemaic Exhibition Development at the Reading Public Museum, Reading PA.

FRANK BENDER is a forensic artist specializing in sculptural reconstructions based on the Gerasimov method. His reconstructions have been used to great effect by the US Marshall Service, the FBI, Surete, and, most recently, by the National Geographic Society.

TRAVIS ALLARD is a graduate student in Anthropology at the University of Manitoba.

ROBERT HOPPA is a Canada Research Chair in Skeletal Biology and Associate Professor of Anthropology at the University of Manitoba. 